\title{
EDUCAÇÃO E SUAS LINGUAGENS: UM ENFOQUE NO EMPREGO EM SALA DE AULA DAS TECNOLOGIAS CULTURAIS E MIDIÁTICAS
}

\author{
doi> http://dx.doi.org/10.33726/akedia2447-7656v5a42018p86-94 \\ Marcelo Pessoa ${ }^{2}-$ iD $_{\text {htps://orcid.org/0000-0002-9193-4604 }}^{3}$ \\ Fabiano Teixeira da Cruz
}

RESUMO: Este paper se preocupa em dar vazão aos estudos realizados sobre a prática didática no ensino de língua e cultura disponibilizado para estudantes do ensino médio. A proposta essencial do texto é a de que se possa subsidiar a comunidade acadêmica, especialmente aos alunos de graduação das Faculdades de Letras e Pedagogia da FACIBRA - Faculdade de Ciências de Wenceslau Braz, no aprendizado teórico do ensino da linguagem e do como melhor difundir os conteúdos aprendidos nas graduações citadas, particularmente aquelas vinculadas ao Departamento de Educação e de Estudos Linguísticos e Literários.

PALAVRAS-CHAVE: Língua Portuguesa, ensino médio, políticas educacionais

ABSTRACT: This paper is concerned to give vent to the studies on practical teaching in the teaching of language and culture made available to high school students.. The essential text is the proposal to subsidize the academic community, especially to the undergraduates of the Faculty of letters and pedagogy of FACIBRA - University of Sciences from the Wenceslau Braz, in theoretical teaching of language learning and of how best spread the contents learned in graduations cited, particularly those linked to the Department of education and Linguistic and literary studies.

KEYWORDS: Language teaching, secondary education, educational policies

\footnotetext{
${ }^{2} \mathrm{O}$ presente texto é uma versão resumida do TCC (Trabalho de Conclusão de Curso), homônimo, desenvolvido sob a orientação do Prof. Fabiano Teixeira da Cruz / da Profa. Dra. Juliane Hartemink Cantini, apresentado à FACIBRA, no final do ano de 2017, como exigência parcial para a obtenção do título de Pedagogo, atendendo aos quesitos normativos exigidos pelo MEC (Ministério da Educação e Cultura), disponíveis em: http://emec.mec.gov.br/emec/consultacadastro/detalhamento/d96957f455f6405d14c6542552b0f6eb/MTY3OA==/c1b85ea4d704f246bcced66 4fdaeddb6/UEVEQUdPR01B, título este obtido por meio do curso de Graduação em Pedagogia como Segunda Licenciatura (vide regime geral de funcionamento do curso em http://emec.mec.gov.br/emec/consultacadastro/detalhamento/d96957f455f6405d14c6542552b0f6eb/MTY3OA==/c1b85ea4d704f246bcced66 4fdaeddb6/UEVEQUdPR01B : e, também, em: http://facibra.edu.br/2a-graduacao/pedagogia/). ${ }^{3}$ Docente e Prof. Orientador do Curso de Pedagogia da FACIBRA.
} 


\section{INTRODUÇÃO}

A presente pesquisa se desenvolveu com o intuito de detectar de que modo as respostas dadas pela universidade para as questões "O que é Ciência?", "O que são as ciências da Linguagem?", bem como, "O que é cultura popular ou erudita?", contribuíram até os dias de hoje para a formação e atuação dos profissionais egressos do Curso de Licenciatura em Pedagogia da FACIBRA - Faculdade de Ciências de Wenceslau Braz, sobretudo quanto à sua prática docente no ensino médio.

Como aporte adicional à compreensão do problema, julgou-se necessário diagnosticar-se a maneira como as tecnologias culturais e midiáticas são utilizadas por estes profissionais e, conforme o perfil de seus estudantes (alunos do ensino médio, por exemplo) tais tecnologias poderiam, de algum modo, ser mais bem empregadas nas salas de aula do ensino médio (nível de escolaridade escolhido pelo egresso e pelo orientador, em função do perfil universitário do formando).

Especificamente, o enfoque do estudo se deu quanto ao modo de ensinar em sala da aula as manifestações linguísticas, sociais e culturais, visando ao formato que as tecnologias servem de incremento ao processo formativo dos egressos do curso de Pedagogia quanto à compreensão que eles poderiam manifestar sobre a utilização das suas competências e habilidades curriculares profissionais no ambiente extramuros universitários.

Nossa pesquisa se justificou na medida em que os resultados de nosso trabalho poderiam, de fato, contribuir para o atendimento da demanda social que existe em torno da promoção de uma melhoria nas condições de ensino das disciplinas do curso de Licenciatura em Pedagogia, especialmente no que tange ao aprimoramento das atuações do futuro pedagogo junto ao público do ensino médio.

Vale salientar que este paper, embora reflexo de estudos referentes ao ensino médio, o que se diz abaixo nos serve também como norte num curso de Licenciatura, tendo em vista que: 
Passados dez anos desde a promulgação da LDB/96, algumas pesquisas indicam que não houve mudanças substanciais na escola, que os documentos são pouco compreendidos pelos professores (Ricardo, 2002; Ricardo e Zylbersztajn, 2002) e pouco discutidos na formação inicial dos novos profissionais, contemporâneos a este processo (Ricardo e Zylbersztajn, 2007). Uma das principais dificuldades para que as mudanças sugeridas tanto nas DCNEM como nos PCN cheguem na sala de aula é a pouca compreensão que os professores têm acerca de temas fundamentais presentes nesses documentos, notadamente, um currículo estruturado por competências, a interdisciplinaridade e a contextualização (RICARDO \& ZYLBERSZTAJN, 2008, p. 258).

que se viu, também, é que é premente a necessidade de se criar alternativas para o ensino de todas as Ciências, pois:

Ainda permanecem alguns problemas que se situam no campo epistemológico. As disciplinas não tratam de objetos reais em sua complexidade. Além disso, é relevante lembrar que há diferenças entre a ciência do cientista e a ciência ensinada na escola. Se o que se espera do aluno é a compreensão de fatos sociais relevantes que envolvam aspectos científicos, muito dificilmente uma disciplina sozinha dará conta desse objeto (RICARDO \& ZYLBERSZTAJN, 2008, p. 266).

Na tentativa de nos aproximarmos, então, do estudante de ensino médio e de questões reais da sociedade, é que nosso artigo propõe um debruçar-se, por meio de várias técnicas, como a realização de grupos de estudos, trabalhos de iniciação científica etc., sobre as interações entre tecnologias linguísticas, culturais e midiáticas em sala de aula.

Como elemento metodológico para a confecção do presente estudo, bem como para a coleta e análise de dados, optamos pela realização de uma pesquisa com enfoque qualitativo, utilizando-se de entrevistas semiestruturadas, cujos personagens foram os discentes ensino médio, os docentes e os funcionários administrativos relacionados às atividades escolares de São José do Rio Preto - SP, durante o ano letivo de 2016-2017.

Assumimos com isso, portanto, que nossa pesquisa teve por natureza de considerar que os resultados e produtos não seriam únicos ou amplamente 
aplicáveis ao contexto do Estado da Paraná (localidade da Faculdade FACIBRA). Por isso, as preocupações deste pesquisador, deram-se prioritariamente sobre o processo de ensino, buscando-se suas causas e relações socioculturais subjacentes para a solução dos problemas em voga.

Ou seja, no decorrer das entrevistas, ao mesmo tempo em que procuramos compreender determinada situação problematizada, realizamos reorientações e adaptações na medida em que as informações foram sendo coletadas e analisadas (adaptado de RICARDO \& ZYLBERSZTAJN, 2008, p. 258).

\section{DESENVOLVIMENTO DA PESQUISA}

Nosso trabalho se desenvolveu necessariamente a partir de um approach multi-, inter- e transdisciplinar, abarcando-se temas das Ciências da língua e da Cultura, deparamo-nos com ambientes em que a compreensão que se tem e se pode ter de sujeito histórico, de sociedade, de espaço e de meio ambiente confluem para a construção de sujeitos estereotipados no contexto do ensino-aprendizagem de língua e de cultura no ensino médio.

Nesse sentido, nosso foco científico se voltou especialmente para a detecção e orientação do como se poderia ter um melhor emprego em sala de aula da produção linguística e cultural disponíveis, especialmente aquelas cujas propostas tenham se dado, de algum modo, sob a batuta dos princípios fundadores das Ciências da Linguagem, da Sociedade e da Cultura:

Acreditamos que a experiência vivida é uma fusão de reapresentações ancoradas, de um lado, em imagens cinemáticas e, de outro, em nossos lugares e práticas. Evidentemente, muito ainda precisa ser dito sobre o retrato cinemático de pessoas e lugares, e como a representação cinemática pode reforçar ou subverter os discursos que constituem as geografias contemporâneas (CORREAA \& ROSENDAHL, 2009, p. 51).

Nosso propósito, então, foi o de incrementar o uso de recursos linguísticos, artísticos e culturais e vê-los sob o enfoque multimídia na sala de 
aula do ensino médio, incentivando-se, com isso, a evolução dos processos educativos sobre os problemas relacionados à prática de reprodução de vídeos e de outras possibilidades culturais durante as aulas.

A reboque disso e com esse fim, portanto, estudamos alguns aspectos da interação discente com as manifestações sociolinguísticas e culturais em uso na sala de aula por parte de alguns docentes, pensando num modo de torná-las mais eficientes, uma vez que em nossa graduação em pedagogia pressupôs-se que, além de estudarmos o uso das novas tecnologias como situação-problema, também reproduziríamos as mesmas práticas em nossas aulas, valendo-nos de conteúdos nesse tipo de mídia.

Desse modo, os resultados de nossos estudos sobre os detalhes dessa interação nos serviram de subsídios basilares para o desenvolvimento de propostas de novos planos de aula para os docentes envolvidos na pesquisa, ao mesmo tempo em que pudemos sugerir no TCC (Trabalho de Conclusão de Curso apresentado ao Curso de Licenciatura em Pedagogia da FACIBRA) o prosseguimento deste eixo temático em outros níveis do ensino, como os de pós-graduação, especialmente naqueles em que se contemplem temáticas com facetas multidisciplinares. Vale dizer, neste sentido, que acreditamos que uma natureza multidisciplinar se vislumbra em nosso artigo, e que, por isso, qualquer proposta resolutiva nesta área devesse ser portadora de um caráter multi -, inter - e transdisciplinar, pois:

\footnotetext{
A interdisciplinaridade, como um movimento contemporâneo que emerge na perspectiva da dialogicidade e da integração das ciências e do conhecimento, vem buscando romper com o caráter de hiperespecialização e com a fragmentação dos saberes (THIESEN, 2008, p. 546).
}

Em nossa pesquisa, viu-se ainda a transdisciplinaridade, posto ao caráter inevitável do diálogo que nele ocorre entre disciplinas como filosofia, história, política, comunicação social, cultura geral e brasileira, figurando esse intercurso como necessidade sine qua non a compreensão do case "ensino médio", face à heterogeneidade do perfil dos agentes envolvidos, os quais são 
dotados de idiossincrasias tão complexas quanto distintas (docentes, discentes, instituição de ensino, sociedade, produção cultural, sociedade etc).

Sem maniqueizar ou ideologizar a questão da presença das tecnologias culturais e eletrônicas em sala de aula, ao lançarmos um olhar ao nosso redor, percebemos que não nos será difícil compreender como que o parcelamento do trabalho na sociedade contemporânea (como o que aconteceu na maioria das atividades profissionais a partir, especialmente, da Revolução Industrial) se tornou cada vez mais especializado e, ao mesmo tempo, paradoxalmente interdependente em relação a outras atividades humanas e habilidades técnicas, exigindo-se dos egressos das universidades competências profissionais cada vez mais diversificadas:

Os hábitos e costumes [que] nos fazem ver a realidade por meio das rotinas, das repetições. [Uma vez que] Eles criam formas peculiares de contemplar o mundo. [Pois], Aquilo que já aconteceu muitas vezes, da mesma maneira, deve continuar a acontecer... Assim, a contragosto somos forçados a admitir que, nas teorias, não são apenas os fatos que falam. É o costume, um fator psicológico, que faz com que liguemos esses fatos de certa forma. Foi-se o ideal de um discurso que enuncia os fatos apenas. Porque aqui, sub-repticiamente, o homem introduz sua crença (ALVES, 2000, p.130-131).

Por isso, a presente proposta textual (ver a íntegra do TCC apresentado à FACIBRA, por meio de solicitação formal por escrito ao banco de dados da IES) intenciona também contribuir para ampliar o leque de reflexões que compõem o currículo do egresso do curso de Pedagogia da FACIBRA, capacitando-o tanto para produzir ciência teórica aplicável à área da linguagem e da cultura em sua relação com as novas tecnologias da comunicação (por meio de iniciação científica, atividades de ensino e de extensão), como também auxiliá-lo na formação de indivíduos capazes de serem agentes multiplicadores e mais eficazes na difusão dos conteúdos aprendidos durante a sua formação.

Desse modo, o pedagogo torna-se agente mais ativo e participante do processo de construção de sua capacitação e da consequente difusão do conhecimento, ao mesmo tempo em que desenvolvedor de novas conexões do saber aplicáveis ao ambiente intramuros da universidade. 


\section{TRATAMENTO DOS DADOS}

Nesta pesquisa, notamos que o alunato (e, em certa medida, também 0 pessoal docente) deseja ter maior contato, ainda que não compreendam totalmente, com experiências artísticas como o cinema (em produções como Dicionário de Cama, de Guy Jenkin, ou Amistad, de Steven Spielberg), a música (em composições como Língua, de Caetano Veloso, ou Apesar de Você, de Chico Buarque), o teatro (em peças como as de Qorpo Santo ou de Sófocles), a pintura (como em quadros de Tarsila do Amaral e de Pablo Picasso), o ativismo político (do Sindicato Solidariedade, do MST, do HAMAS etc.), e a luta de classes (como a que se dá entre os protagonistas da riqueza e da desigualdade brasileira), a literatura (nos impactantes textos do brasileiro Nelson Rodrigues, ou nos emblemáticos romances do colombiano Gabriel García Márquez, ou no experimentalismo poético multimídia do demiurgo linguístico e musical Arnaldo Antunes), a preservação ambiental e a intervenção antrópica no meio ambiente (que põem num mesmo palco de discussão as ações do Greenpeace e a militância político-partidária de Marina Silva e Albert Arnold "Al" Gore), o folclore (ficcional de Monteiro Lobato, literário e histórico de Euclides da Cunha e Guimarães Rosa e o científico de Darci Ribeiro) foram vistos como fontes de pesquisa, uma vez que serviram de ponte interativa, ao mesmo tempo em que lúdicas, metalinguísticas, entre a universidade, o estágio pré-serviço exigido ao futuro pedagogo e a sociedade, reveladoras da cultura e explicativas da tecnologia e, por isso, parte importante e até mesmo determinante para a construção e difusão do conhecimento aqui reproduzido por meio dos estudos realizados no conjunto das disciplinas do curso de Pedagogia como segunda licenciatura.

Convém dizer também que, num trabalho como este, se tivemos a virtude de fomentar ainda a ideia de que o profissional da Linguística, da Cultura ou das Ciências da Linguagem deve sempre pautar sua conduta no sentido de estreitar os contatos de sua área de conhecimento com as demais 
disciplinas do saber constituído, especialmente aquelas ligadas às ciências humanas (ALMEIDA, 2009), isto não é mera coincidência, mas condição igualmente sine qua non para a solidificação da qualidade dos egressos dos cursos de Letras e de Pedagogia oriundos da FACIBRA.

Finalmente, é válido dizer, que após o seu período básico de formação regular na graduação, o egresso participante de nosso estudo poderá indubitavelmente poderá exercitar competências e habilidades que transcendem a grade curricular tradicional de seu curso, mas que são fundamentais para o exercício profissional extramuros universitários da contemporaneidade.

\section{CONCLUSÕES}

Com nossa pesquisa esperamos poder contribuir para melhorar a formação recursos humanos, incrementando suas capacitações na área da Linguística, da Cultura e das Ciências da Linguagem, uma vez que os estudantes envolvidos poderão desenvolver competências adicionais à sua formação principal em pedagogia, que os permitam atuar profissional e humanamente de modo diferenciado diante de situações reais após o período de suas respectivas formações básicas obtidas na universidade.

Desejamos também que o presente texto contribua para a mitigação dos problemas relacionados ao desenvolvimento de competências e habilidades para o exercício profissional extramuros universitários, particularmente no contexto do ensino médio frente às novas tecnologias da comunicação.

Por fim, pretendemos que nosso paper seja capaz de subsidiar pesquisas futuras na área das Ciências da Linguagem e da Cultura, especialmente no que tange à produção e difusão do conhecimento, tendo em vista que, ao lado do TCC ora entregue, publicaremos artigos científicos anunciando nossos resultados. 


\section{REFERÊNCIAS}

(OBS.: Nestas referências incluem-se todo o aporte bibliográfico na íntegra do TCC entregue à FACIBRA. Na síntese que se publica aqui por meio de um artigo científico, optamos por manter todos os títulos empregado no original da monografia, em função de se desejar fomentar novos estudos a partir do acervo ora indicado)

ABRUZZESE, Alberto. O Esplendor da Linguagem Audiovisual. São Paulo: Studio Nobel, 2006.

ALVES, Rubem. A morte como conselheira. In: CASSORLA, Roosevelt M. S. (Coord). Da morte. Campinas: Papirus, 1991.

ALVES, Rubem. Filosofia da Ciência. São Paulo: Loylola, 2000.

ALVES, Giovanni. Tela Crítica - a metodologia. Londrina; Praxis, Bauru: Canal 6, 2010.

BIZZOCCHI, Aldo. Anatomia da Cultura. São Paulo: Palas Athena, 2003.

CAVALCANTI, Clóvis (org.). Desenvolvimento e Natureza - estudos para uma sociedade sustentável. São Paulo: Cortez; Recife, PE: Fundação Joaquim Nabuco, 2001.

CHAUÍ, Marilena. Cultura e Democracia: o discurso competente e outras falas. São Paulo: Moderna, 1981.

CHAUI, Marilena. Convite à Filosofia. São Paulo: Ática, 1997.

CHAUÍ, Marilena. Simulacro e Poder. São Paulo: Perseu Abramo, 2006.

CLAVAL, Paul. Epistemologia da Geografia. Florianópolis: UFSC, 2011.

COMPAGNON, Antoine. O Demônio da Teoria. Belo Horizonte: UFMG, 2010.

CORRÊA, Roberto Lobato; ROSENDAHL, Zeny (orgs.). Cinema, Música e

Espaço. Rio de Janeiro: EdUERJ, 2009.

FELDMAN-BIANCO, Bela (org.). Antropologia das Sociedades

Contemporâneas - métodos. São Paulo: UNESP, 2010.

FERRARA, Lucrecia D'Aléssio. Leitura sem Palavras. São Paulo: Ática, 2007.

FISCHER, Steven Roger. Uma Breve História da Linguagem. Osasco, SP:

Novo Século, 2009.

GOMES, Salatiel Ribeiro. História e Cinema - sertão e redenção em Deus e o

Diabo na Terra do Sol. São Paulo: AnnaBlume, 2011.

HISSA, Cássio Eduardo Viana (org.). Saberes Ambientais. Belo Horizonte:

UFMG, 2008.

HOBSBAWN, Eric J. Mundos do Trabalho. São Paulo: Paz e Terra, 2008.

KUNCZIK, Michael. Conceitos de Jornalismo. São Paulo: USP, 2001.

LENTZ, Luiza Maria. Fotografia do Cotidiano: a consagração do instante em Rubem Braga e Alice Ruiz. (Dissertação de Mestrado). UEL - Universidade Estadual de Londrina, Londrina, 2006.

LIMA, Edvaldo Pereira. Páginas Ampliadas - o livro-reportagem como extensão do jornalismo e da literatura. Barueri, São Paulo: Manole, 2009. 
MARANDOLA Jr., Eduardo; GRATÃO, Lúcia Helena Batista (orgs.). Geografia e Literatura - ensaios sobre geograficidade, poética e imaginação. Londrina: EDUEL, 2010.

MEIHY, José Carlos Sebe B.; HOLANDA, Fabíola. História Oral - como fazer, como pensar. São Paulo: Contexto, 2010.

MEYER, Mônica. Ser-tão Natureza - a natureza em Guimarães Rosa. Belo Horizonte: UFMG, 2008.

NETO, Jamil Zugueib (org.). Identidades e Crises Sociais na

Contemporaneidade. Curitiba: UFPR, 2005.

PILETTI, Nelson \& PILETTI, Claudino. História da Educação. São Paulo: Ática, 2002.

PILETTI, Claudino \& PILETTI, Nelson. Filosofia e História da Educação. São Paulo: Ática, 2002.

PLAISANCE, Patrick Lee. Ética na Comunicação - princípios para uma prática responsável. Porto Alegre: Penso, 2011.

RAVETTI, Graciela et al (orgs.). Topografias da Cultura - representação, espaço e memória. Belo Horizonte: UFMG, 2009.

RICARDO, Elio Carlos; ZYLBERSZTAJN, Arden. OS PARÂMETROS CURRICULARES NACIONAIS PARA AS CIÊNCIAS DO ENSINO MÉDIO: UMA ANÁLISE A PARTIR DA VISÃO DE SEUS ELABORADORES.

Investigações em Ensino de Ciências - V13(3), p.257-274, disponível em http://www.if.ufrgs.br/ienci/artigos/Artigo ID195/v13 n3 a2008.pdf, acesso em 27/04/2012, às 16h:35m.

ROSSO, Mauro (org.). Escritos de Euclides da Cunha - política, ecopolítica, etnopolítica. Rio de Janeiro: PUC-Rio, 2009.

SILVA FILHO, Antônio Carlos Pacheco. Cinema, Literatura e Psicanálise. São Paulo: EPU, 1988.

SILVA, Dinorá Fraga \& FRAGOSO, Suely. Comunicação na Ciber Cultura. São Leopoldo: UNISINOS, 2001, p. 105-115.

SILVEIRA, Nise da. O Mundo das Imagens. São Paulo: Ática, 1992.

SONTAG, Susan. Sobre Fotografia. São Paulo: Cia. das Letras, 2004.

THIESEN, Juares da Silva. A interdisciplinaridade como um movimento articulador no processo ensino-aprendizagem. In: Revista Brasileira de Educação, v. 13, n. 39, set./dez. 2008, p. 545-554. Disponível em http://www.anped.org.br/rbe/numeros_rbe/rbe39-miolo.pdf.

VELHO, Gilberto. Mudança, Crise e Violência. Rio de Janeiro: Civilização Brasileira, 2002.

XAVIER, Ismail. O Discurso Cinematográfico: a opacidade e a transparência. Rio de Janeiro: Paz e Terra, 1977.

ZUMTHOR, Paul. O Espaço Oral. A Letra e a Voz. São Paulo: Cia. das Letras, 1993, p. 35-116. 